\title{
HUBUNGAN DUKUNGAN PERAN KELUARGA DENGAN KELENGKAPAN IMUNISASI DASAR DPT ANAK DI DESA PAMOLAAN TANJUNG KABUPATEN SAMPANG TAHUN 2018
}

Nur Imanah, Puskesmas Tanjung kabupaten Sampang

e-mail: nurimanah@gmail.com

\section{ABSTRACT}

The coverage of basic DPT immunization has decided $90 \%$ by government In fact, the coverage of basic DPT immunization in Pamolaan does not complete the target yet. The first DPT is around $85.8 \%$, the second DPT is $71 \%$, and the last DPT is $67.9 \%$. Family's support and role is one of factor that influences the completeness of basic DPT immunization. But until now, the correlation between family's support and role with completeness of the basic DPT immunization for children doesn't explain yet. This study was aimed to identify the correlation between family's support and role with completeness of the basic DPT immunization.

Design used in this study was cross sectional. The populations of the study were mother who has children at the age of six months to twelve months. Sample, enrolled using purposive sampling and total sample was fifty respondents who had been taken according to inclusion criteria. Independent variable was family's support and role in completing basic DPT immunization. The dependent variable was the completeness of basic DPT immunization for children. Data were collected using Sperman and Chi square statistical test with significance level $p<0.05$.

Results showed that there is correlation between family's support with completeness of the basic DPT immunization with correlation significant $(p=0.045)$ and correlation coefficient $(r=0.285)$. Then, there is correlation between family's role with completeness of the basic DPT immunization with correlation significant $(p=0.001)$ and contingency coefficient $(C=0.474)$.

It can be concluded that there are correlation between family's support and role by showing a moderate correlation. So, family's support and role can become reinforcing factor for mother to give DPT immunization for children but not the dominant factor.

\section{Keywords: family's support, family's role, the completeness of basic DPT immunization}

\section{PENDAHULUAN}

Imunisasi merupakan program preventif utama dalam rangka menurunkan angka kematian bayi dan balita. Salah satu jenis imunisasi yang diwajibkan oleh pemerintah adalah imunisasi DPT (Difteri, Pertusis, dan Tetanus) (Pusat Pelatihan dan Penelitian, 2014). Pada kenyataanya tingkat drop out imunisasi DPT lebih banyak daripada imunisasi lain yang juga memerlukan dosis yang bertahap sehingga masih banyak anak yang belum memiliki status imunisasi DPT lengkap. Cakupan imunisasi dibeberapa daerah di Indonesia terutama Jawa Timur masih rendah dan belum mencapai standart yang ditetapkan oleh WHO yang berdasarkan standart UCI (Universal Child Immunization) yaituminimal $90 \%$ dari jumlah bayi yang ada di daerah tersebut (Dinkes Surabaya, 2016). Menurut data laporan hasil imunisasi bayi Kabupaten Sampang Bulan Januari s/d Desember Tahun 2017, ada puskesmas yang cakupan imunisai DPT sudah lengkap memenuhi standart $\mathrm{UCl}$ yaitu $90 \%$. Akan tetapi ada Desa di bawah wilayah Kerja Puskesmas Tanjung yang mempunyai cakupan imunisasi dasar DPT rendah yaitu Desa Pamolaan. Cakupan imunisasi DPT di Desa Pamolaan Kecamatan Camplong pada periode Bulan Januari sampai dengan Bulan Desember tahun 2017 yaitu DPT $1(78,82 \%)$, DPT 2 (71,7\%), dan DPT 3 (50,58\%) dengan tingkat droup out $49,41 \%$ (Dinkes Sampang, 2017). Cakupan imunisasi tersebut belum mencapai target UCldan target yang ditetapkan oleh Kantor Wilayah Kabupaten Sampang yaitu DPT1 (90\%), DPT 2 (90\%), dan DPT 3 (85\%). Menurut hasil penelitian, faktor-faktor yang mempengaruhi kelengkapan imunisasi dasar termasuk DPT adalah pekerjaan ibu, tingkat pendidikan ibu, tingkat pengetahuan ibu, efek vaksin, factor jumlah anak balita, dan jarak rumah ke tempat pelayanan imunisasi. Dukungan keluarga juga berpengaruh pada kelengkapan imunisasi dasar termasuk imunisasi DPT karena merupakan pendorong utama ibu untuk melakukan imunisasi. Menurut hasil wawancara dengan petugas Puskesmas Tanjung dan ibu balita, anak tidak mendapat imunisasi DPT lengkap karena dilarang oleh suami/anggota keluarga yang lain dengan 
alasan efek demam setelah diimunisasi. Program penyuluhan tentang imunisasi di Puskesmas Tanjung dilaksanakan tiap 1 kali dalam sebulan. Tidak lengkapnya imunisasi dasar DPT jelas terlihat dari survey awal yang diperoleh peneliti, dimana cakupan imunisasi masih dibawah target $90 \%$ yang menandakan status imunisasi dasar DPT anak di Puskesmas Tanjung Kabupaten Sampang belum lengkap. Sampai saat ini, hubungan antara dukungan dan peran keluarga dengan kelengkapan imunisasi dasar DPT belum dapat dijelaskan.

Faktor yang mempengaruhi perilaku yang berhubungan dengan kesehatan menurut teori dari Lawrence Green adalah faktor predisposisi (predisposising factors), faktor pendukung (enabling factors), dan faktor pendorong (reinforcing factor). Dukungan dan peran keluarga merupakan faktor pendorong kepada ibu untuk melakukan imunisasi DPT pada anak (Notoatmodjo, 2013). Dukungan keluarga dapat berupa saran, informasi, dukungan emosi, penyediaan fasilitas dan lain-lain (Friedman, 1998). Peran keluarga dapat berupa perhatian anggota keluarga dalam pemberian imunisasi anak (Efendi dan Makhfudli, 2015). Manfaat keterlibatan keluarga akan meningkatkan kesehatan/kesejahteraan anggota keluarga termasuk kesehatan anak. Sama halnya dalam pemberian imunisasi DPT jika dukungan dan peran keluarga diberikan maka ibu terdorong mengimunisasi anak untuk menjaga kesehatan anak. Jika tidak ada dukungan dan peran keluarga dalam pemberian imunisasi DPT, maka status kelengkapan imunisasi DPT anak menjadi tidak lengkap dan tidak memiliki kekebalan terhadap penyakit Difteri, Pertusis, dan Tetanus (Unicef, 2015).

Pemerintah telah memberi perhatian dalam meningkatkan kelengkapan imunisasi dasar termasuk imunisasi DPT melalui Pengembangan Program Imunisasi (PPI) dengan cara meningkatkan sarana prasarana kesehatan dan meningkatkan mutu pelayanan. Pemerintah juga mencanangkan program sweeping imunisasi door to door. Selain itu, program yang telah dilakukan pemerintah adalah sosialisasi program ke-38 kota yang ada di Jatim melalui workshop serta sharing bersama dengan para mitra dan melakukan pemantauan program imunisasi termasuk imunisasi DPT di tiap-tiap kota dan kabupaten (Dinkes Surabaya, 2015). Program sosialiasi imunisasi juga dilakukan oleh
Dinkes di Jawa Timur dengan mengandeng beberapa lembaga seperti Majelis Ulama Indonesia (MUI), PKK, dan Pramuka untuk membantu mensosialisasikan pentingnya imunisasi. Program advokasi terhadap masyarakat termasuk keluarga dan orang tua juga perlu dilakukan oleh petugas kesehatan agar memberikan dukungan terhadap pelayanan imunisasi. Program-progam tersebut diharapkan dapat meningkatkan cakupan imunisasi termasuk imunisasi dasar DPT di Jawa Timur agar mencapai target imunisasi yang telah ditetapkan pada tahun 2017 yaitu mencapai 100\%. Program pemerintah tentang imunisasi tersebut, dapat memberikan perlindungan kepada anak dengan cara memberi system kekebalan sehingga dapat menjaga kesehatan anak dari penyakit menular (Pusat Pendidikan dan Pelatihan, 2014). Oleh karena itu diperlukan dukungan dan peran keluarga yang baik untuk memperlancar program pemerintah dalam rangka meningkatkan kelengkapan imunisasi dasar anak khususnya imunisasi DPT.

\section{METODE PENELITIAN}

Desain Penelitian yang digunakan dalam penelitian ini adalah cross sectional, populasinya adalah ibu yang mempunyai balita usia 6-12 bulan di Desa Pamolaan ssejumlah 57 orang, Sampel dalam penelitian ini adalah yamg memenuhi kriteria inklusi antara lain: Ibu yang mempunyai anak usia 612 bulan dan Bersedia untuk mengikuti dalam penelitian dan didapatkan 50 sampel. analisa data menggunakan uji chi square.

\section{HASIL PENELITIAN}

Tabel 1 Tabulasi silang hubungan dukungan keluarga dengan kelengkapan imunisasi DPT anak

\begin{tabular}{cccc}
\hline \multirow{2}{*}{$\begin{array}{c}\text { Dukungan } \\
\text { Keluarga }\end{array}$} & \multicolumn{2}{c}{$\begin{array}{c}\text { Kelengkapan } \\
\text { imunisasi DPT anak }\end{array}$} & Total \\
\cline { 2 - 3 } & $\begin{array}{c}\text { Tidak } \\
\text { Lengkap }\end{array}$ & Lengkap & \\
\hline \multirow{2}{*}{ Kurang } & 10 & 1 & 11 \\
& $(90.9 \%)$ & $(9.1 \%)$ & $-100 \%$ \\
Cukup & 16 & 15 & 31 \\
& $(51.6 \%)$ & $(48.4 \%)$ & $-100 \%$ \\
Baik & 4 & 4 & 8 \\
& $-50 \%$ & $-50 \%$ & $-100 \%$ \\
Total & 30 & 20 & 50 \\
& $-60 \%$ & $-40 \%$ & $-100 \%$ \\
\hline
\end{tabular}

Koefisien Korelasi $(r)=0.285 p=0,045$ 
Dari tabel 1 dapat diidentifikasi bahwa paling banyak keluarga memberikan dukungan yang cukup kepada ibu untuk melengkapi imunisasi DPT anak dan status imunisasi pada ketiga kategori dukungan termasuk tidak lengkap dan terbanyak pada dukungan cukup yaitu sebanyak 16 orang $(51.6 \%)$. Dukungan keluarga yang paling sedikit diberikan kepada ibu untuk melengkapi imunisasi DPT anak adalah dukungan baik sehingga menyebabkan anak yang mempunyai status imunisasi DPT lengkap dan tidak lengkap sama jumlahnya yaitu sebanyak 4 orang (50.0\%). Hasil uji sperman terdapat hubungan dukungan keluarga dengan kelengkapan imunisasi DPT anak dengan tingkat signifikansi $p=0,045$ dan koefisien korelasi $(r)$ sebesar 0.285 . Hal ini berarti $\mathrm{H} 1$ diterima dan hubungan (korelasi) antara dukungan keluarga dengan kelengkapan imunisasi dasar DPT anak mempunyai hubungan tingkat sedang.

Tabel 2 Tabulasi silang hubungan peran keluarga dengan kelengkapan imunisasi DPT anak

\begin{tabular}{cccc}
\hline \multirow{2}{*}{$\begin{array}{c}\text { Peran } \\
\text { Keluarga }\end{array}$} & \multicolumn{2}{c}{$\begin{array}{c}\text { Kelengkapan imunisasi } \\
\text { DPT anak }\end{array}$} & \multirow{2}{*}{ Total } \\
\cline { 2 - 3 } & Tidak Lengkap & Lengkap & \\
\hline \multirow{2}{*}{ Kurang } & 18 & 3 & 21 \\
& $(85.7 \%)$ & $(14.3 \%)$ & $-100 \%$ \\
Cukup & 9 & 6 & 15 \\
& $-60 \%$ & $-40 \%$ & $-100 \%$ \\
Baik & 3 & 11 & 14 \\
& $(21.4 \%)$ & $(78.6 \%)$ & $-100 \%$ \\
Total & 30 & 20 & 50 \\
& $-60 \%$ & $-40 \%$ & $-100 \%$ \\
\hline
\end{tabular}

Koefisien Kontingensi (C) $=0.474 p=0,001$

Dari tabel 2 dapat diidentifikasi bahwa

paling banyak ibu merasakan peran keluarga yang kurang dalam melengkapi imunisasi DPT anak sehingga status imunisasi DPT anak tidak lengkap sebanyak 18 orang $(85.7 \%)$. Sedangkan peran keluarga yang paling sedikit dirasakan oleh ibu dalam melengkapi imunisasi DPT anak adalah peran keluarga baik sehingga anak memiliki status imunisasi DPT tidak lengkap yaitu sebanyak 3 orang (21.4\%). Hasil uji chi square menyatakan bahwa terdapat hubungan peran keluarga dengan kelengkapan imunisasi DPT anak dengan tingkat signifikansi $p=0,001$ dan koefisien kontingensi $(C)$ sebesar 0.474 . Hal ini berarti $\mathrm{H} 1$ diterima danhubungan (korelasi) peran keluarga dengan kelengkapan imunisasi DPT anak mempunyai hubungan tingkat sedang.

\section{PEMBASAHAN}

\subsection{Hubungan dukungan keluarga dengan kelengkapan imunisasi dasar DPT anak}

Penelitian ini menunjukkan bahwa sebagian besar dukungan keluarga yang diberikan kepada ibu untuk melengkapi imunisasi DPT anak sudah cukup diberikan seperti dukungan emosional, dukungan penghargaan, dukungan instrumental/fasilitas dan dukungan informasi. Menurut Setiadi (2008), dukungan keluarga terdiri dari 4 jenis yaitu dukungan instrumental, dukungan informational, dukungan penilaian, dan dukungan emosional. Hal tersebut didukung karena sebagian besar balita merupakan anak pertama dari keluarga sehingga keluarga lebih perhatian kepada anak untuk melengkapi imunisasi DPT anak. Hal itu sesuai dengan teori yang mengatakan bahwa anak pertama merupakan curahan kasih sayang dan perhatian keluarga (Setiawati dan Anita, 2017). Selain itu, dukungan yang cukup juga diberikan oleh keluarga karena lebih dari separuh keluarga juga tidak mempunyai anak balita lainnya yang berusia antara 13 bulan- 5 tahun karena menurut teori faktor jumlah anak balita yang dimiliki berpengaruh terhadap kelengkapan imunisasi anak dan juga sesuai dengan pendapat Soetjiningsih (1995) yang mengatakan bahwa jumlah anak yang banyak akan mengakibatkan berkurangnya kasih sayang dan perhatian juga kebutuhan primer termasuk juga kesehatan anak.

Dukungan yang paling sedikit diberikan oleh keluarga kepada ibu adalah dukungan informasi. Menurut teori pemberian informasi tentang pemeliharaan kesehatan dan cara menghindari penyakit akan meningkatkan pengetahuan seseorang (keluarga) tentang hal tersebut sehingga akan mendorong seseorang untuk bertindak atau melakukan sesuatu (Notoatmodjo, 2015). Dukungan informasi yang sedikit disebabkan kurangnya informasi yang diberikan oleh petugas kesehatan tentang imunisasi DPT kepada keluarga dan hanya diberikan penyuluhan kepada ibu balita. Dukungan informasi yang kurang diberikan oleh keluarga dalam penelitian ini berupa informasi tentang imunisasi DPT meliputi manfaat dan efek samping imunisasi DPT, informasi dalam mengingatkan jadwal pemberian imunisasi DPT, informasi dalam mengingatkan akibat 
jika anak tidak mendapatkan imunisasi DPT lengkap dan informasi mengenai hal-hal yang tidak jelas tentang imunisasi DPT ketika ibu bertanya kepada keluarga.

Berdasarkan hasil hasil penelitian juga ditunjukkan bahwa lebih dari 50\% anak mempunyai status imunisasi DPT tidak lengkap. Hal ini dipengaruhi oleh tingkat pendidikan ibu yang sebagian besar berpendidikan SD (44\%) karena menurut Soetjiningsih (1995) mengatakan bahwa pendidikan orang tua termasuk ibu merupakan salah satu faktor yang penting dalam tumbuh kembang dan kesehatan anak, karena dengan pendidikan yang baik orang tua dapat menerima segala informasi dari luar terutama tentang cara bagaimana menjaga kesehatan anaknya termasuk informasi tentang pentingnya kelengkapan imunisasi DPT bagi kesehatan anak sehingga pendidikan seseorang khususnya seorang ibu akan mengubah sikapnya terhadap sesuatu yang dalam hal ini adalah sikap terhadap imunisasi, kemudian sikap tersebut terlihat dalam praktek imunisasi termasuk imunisasi DPT.Menurut Teori Lawrance Green dalam Notoatmojo (2015) mengatakan bahwa pendidikan ibu merupakan salah satu faktor yang mempengaruhi kelengkapan imunisasi anak termasuk imunisasi DPT. Selain itu kelengkapan imunisasi dasar DPT anak juga dipengaruhi oleh usia balita karena menurut hasil penelitian paling banyak balita berumur 12 bulan dan paling sedikit berumur 6 bulan. Jadi balita yang mempunyai umur 12 bulan mempunyai waktu yang lebih lama untuk melengkapi imunisasi dasar DPT daripada balita yang masih berumur 6 bulan apabila balita tersebut tidak memulai imunisasi DPT yang pertama tepat pada usia 2 bulan atau telat dalam pemberian imunisasi DPT yang pertama. Hal tersebut didukung oleh teori yang mengatakan bahwa dosis pertama diberikan diberikan pada umur 2 bulan, dosis selanjutnya diberikan dengan interval paling cepat 4 minggu (1 bulan) dan jarak pemberian antara DPT 1 dan DPT 2 maksimal 6-8 minggu. Selain itu, pemberian imunisasi dasar DPT bisa dilakukan sebelum anak berusia 1 tahun (Unicef, 2009). Jadi semakin tua umur anak maka mempunyai kesempatan yang lebih lama untuk melengkapi status imunisasi DPT.

Berdasarkan hasil hasil tabulasi silang, terdapat responden (1 orang) yang kurang mendapatkan dukungan dari keluarga tetapi mempunyai status imunisasi yang lengkap.
Hal tersebut bisa disebabkan karena ibu mempunyai pengetahuan yang baik terhadap kelengkapan imunisasi DPT anak karena sering mengikuti penyuluhan tentang manfaat kelengkapan imunisasi DPT bagi anak di Puskesmas maupun di Posyandu. Pengetahuan ibu tersebut juga bisa dipengaruhi oleh faktor usia ibu yang lebih dari separuh berusia 22-44 tahun yang menandakan bahwa ibu berada dalam rentang usia dewasa sehingga masih semangat untuk mencari pengetahuan dan giat membawa anak ke tempat pelayanan imunisasi untuk mendapatkan imunisasi DPT meskipun tidak mendapatkan dukungan maupun peran dari keluarga.

Berdasarkan uji statistik didapatkan hubungan antara dukungan keluarga dengan kelengkapan imunisasi DPT anak dengan tingkat hubungan sedang. Hal tersebut sejalan dengan teori Lawrance Green dan Judith yang mengatakan bahwa dukungan keluarga akan mendorong seseorang untuk melakukan sesuatu karena dukungan dari keluarga merupakan faktor reinforcingbagi untuk berperilaku baik dalam memberikan imunisasi DPT kepada anak. Jadi, ibu yang kurang mendapatkan dukungan dari keluarga untuk melengkapi imunisasi DPT anak tidak akan terdorong untuk melakukan imunisasi DPT terhadap anak sehingga status imunisasi DPT di Desa Pamolaan Kabupaten Sampang sebagian besar tidak lengkap. Selain itu, hasil penelitian ini sesuai dengan teori yang mengatakan bahwa dukungan sosial keluarga yang adekuat memberikan pengaruh positif terhadap kesehatan/kesejahteraan keluarga (Setiadi, 2015). Hal tersebut diperkuat oleh teori dari Friedman yang mengatakan bahwa dukungan keluarga merupakan salah satu faktor yang sangat berpengaruh terhadap perilaku positif seseorang. Hubungan dengan tingkat sedang antara dukungan keluarga dengan kelengkapan imunisasi DPT anak disebabkan karena karena ada faktor dominan lain misalnya faktor pendidikan ibu, karena sebagian besar (44\%) tingkat pendidikan ibu adalah SD sehingga meskipun ibu mendapat dukungan dari keluarga untuk mengimunisasi anak, mereka tidak melakukan imunisasi anak karena kurangnya tingkat pengetahuan ibu tentang kelengkapan imunisasi DPT. Faktor dominan yang lain adalah faktor pengetahuan keluarga yang mempengaruhi hubungan antara dukungan keluarga dengan kelengkapan imunisasi anak karena teori mengatakan bahwa jika 
seseorang tahu dari informasi atau pengalaman sendiri maupun pengalaman orang lain, maka seseorang tersebut akan melakukan tindakan sesuai dengan kebutuhannya (Notoatmojo, 2015). Hubungan antara dukungan keluarga dan kelengkapan imunisasi DPT anak yang termasuk dalam tingkat sedang juga bisa disebabkan karena faktor jarak rumah responden yang agak jauh $(>1 \mathrm{~km})$ ke tempat pelayanan imunisasi tidak menjadi masalah bagi responden karena keluarga tetap memberikan dukungan instrumental berupa menyediakan waktu dan fasilitas untuk mengantar ibu untuk melengkapi imunisasi dasar DPT anak.

Penelitian ini pernah dilakukan oleh Devit (2007) dengan hasil bahwa dukungan keluarga merupakan salah satu faktor yang berpengaruh pada kelengkapan imunisasi dasar termasuk imunisasi DPT karena merupakan pendorong utama ibu untuk melakukan imunisasi dan hasil penelitian ini mengatakan bahwa ada hubungan dukungan keluarga dengan kelengkapan imunisasi DPT anak dimana kuat rendahnya dukungan keluarga akan berpengaruh terhadap perilaku ibu dalam melakukan imunisasi DPT pada anak sehingga berpengaruh pada kelengkapan imunisasi DPT anak. Berdasarkan hasil penelitian, dukungan keluarga yang kurang, maka perlu dilakukan intervensi berupa penyuluhan kepada masyarakat tentang pentingnya dukungan keluarga pada waktu posyandu.

\section{Hubungan peran keluarga dengan kelengkapan imunisasi dasar DPT anak}

Hasil penelitian ini menunjukkan bahwa sebagian besar peran keluarga yang dirasakanoleh ibu dalam melengkapi imunisasi DPT anak dalam tingkat kurang.Peran keluarga yang kurang ditunjukkan dengan data hanya sedikit keluarga yang memberikan dukungan baik kepada ibu dalam mengimunisasi DPT anak sehingga perannya menjadi kurang. Peran keluarga yang paling kurang dirasakan oleh ibu berupa peran keluarga dalam mengenal masalah kesehatan. Menurut teori, pengetahuan keluarga dalam mengenal masalah kesehatan anak merupakan domain yang sangat penting dalam membentuk tindakan seseorang (Notoatmojo, 2015). Hal tersebut dapat terjadi karena dukungan informasi yang diberikan oleh keluarga sangat sedikit sehingga perannya pun kurang terhadap kelengkapan imunisasi DPT anak.
Dalam penelitian ini, keluarga kurang mengetahui tentang imunisasi DPT khususnya pengertian, manfaat, dan akibat dari kelengkapan imunisasi DPT terhadap kesehatan anak sehingga peran yang diberikan keluarga untuk melengkapi imunisasi DPT kurang. Selain itu, menurut Lawrence Green dan Judith pengetahuan keluarga dalam mengenal masalah kesehatan anggota keluarga merupakan faktor predisposisi/pemicu terhadap ibu untuk melakukan perilaku kesehatan dalam hal ini perilaku dalam melengkapi imunisasi DPT anak sebagai usaha untuk mencegah penyakit Difteri, Pertusis, dan Tetanus terhadap anak. Peran keluarga yang kurang dalam mengenal masalah kesehatan anak pada penelitian ini meliputi keluarga kurang mengetahui pengertian imunisasi DPT, manfaat imunisasi DPT, akibat jika anak tidak mendapatkan imunisasi DPT dan persepsi yang kurang baik terhadap manfaat kelengkapan imunisasi DPT bagi anak.

Hasil penelitian ini juga menunjukkan bahwa lebih dari $50 \%$ anak mempunyai status imunisasi DPT tidak lengkap. Hal ini dipengaruhi oleh tingkat pendidikan ibu yang sebagian besar berpendidikan SD. Menurut teori, pendidikan orang tua merupakan faktor penting dalam tumbuh kembang dan kesehatan anak, karena dengan pendidikan yang baik orang tua dapat menerima segala informasi dari luar terutama tentang bagaimana menjaga kesehatan anak (Soetjiningsih, 1995). Informasi dalam menjaga kesehatan anak dapat berupa informasi tentang pentingnya kelengkapan imunisasi DPT bagi kesehatan anak. Selain itu, teori Lawrance Green dalam Notoatmojo (2015) mengatakan bahwa pendidikan ibu merupakan salah satu faktor yang mempengaruhi kelengkapan imunisasi anak termasuk imunisasi DPT sehingga pendidikan ibu juga berpengaruh pada kelengkapan imunisasi DPT anak. Tetapi dari hasil tabulasi, ada juga responden yang memiliki tingkat pendidikan yang lebih rendah namun status kelengkapan imunisasi DPT anak lengkap dan sebaliknya responden yang memiliki tingkat pendidikan tinggi malah mempunyai status imunisasi DPT tidak lengkap. Hal tersebut bisa dipengaruhi karena dukungan dan peran keluarga yang diberikan pada ibu yang berpendidikan rendah sangat baik dan dukungan dan peran keluarga kurang diberikan kepada ibu yang berpendidikan tinggi. Jadi meskipun ibu mempunyai 
pendidikan tinggi, tidak mutlak menyebabkan status imunisasi DPT anak menjadi lengkap karena ada faktor dari keluarga yang juga mempengaruhi kelengkapan imunisasi DPT anak sesuai dengan teori Friedman yang mengatakan bahwa keluarga memainkan peranan vital dalam upaya peningkatan kesehatan dan pengurangan resiko terhadap masalah kesehatan anggota keluarga, termasuk kesehatan anak. lbu yang berpendidikan tinggi tapi mempunyai anak yang memiliki status kelengkapan imunisasi DPT tidak lengkap juga bisa dipengaruhi karena ibu yang berpendidikan tinggi cenderung bekerja sehingga mempunyai sedikit waktu untuk memeperhatikan kebutuhan primer anak termasuk kesehatan anak.

Menurut uji statistik didapatkanhubungan peran keluarga dengan kelengkapan imunisasi anak dengan tingkat sedang. Hasil penelitian ini sesuai dengan teori dari Friedman (2010) yang mengatakan bahwa manfaat keterlibatan keluarga akan meningkatkan kesehatan/kesejahteraan anggota keluarga termasuk meningkatkan kelengkapan imunisasi dasar DPT anak sebagai upaya untuk melindungi anak dari penyakit Difteri, Pertusis, dan Tetanus. Korelasi dengan tingkat sedang antara peran keluarga dengan kelengkapan imunisasi anak mungkin disebabkan karena karena sebagian besar tingkat pendidikan ibu adalah SD sehingga meskipun ibu merasakan peran yang baik dari keluarga untuk mengimunisasi anak, mereka tidak melakukan imunisasi anak karena kurangnya tingkat pengetahuan ibu tentang kelengkapan imunisasi DPT. Selain itu bisa disebabkan karena pekerjaan responden yaitu wiraswasta yang merupakan pekerjaan paling banyak ke-2 sehingga ibu atau keluarga sibuk dengan pekerjaannya sehingga tidak mengimunisasi anak ketika ada posyandu atau tidak punya waktu untuk membawa anak ke puskesmas untuk mengimunisasi DPT anak karena menurut teori ibu yang bekerja termasuk wiraswata mempunyai kesempatan meluangkan waktu yang kecil untuk mengurus anak (Sastrohadiwiryo, 2015). Mengingat peran keluarga selaras dengan kelengkapan imunisasi DPT anak, maka partisipasi keluarga sangat dibutuhkan oleh ibu balita ketika anak mendapat imunisasi DPT. Pada Penelitian ini, dukungan dan peran keluarga bukan merupakan faktor dominan dalam kelengkapan imunisasi DPT anak karena tingkat korelasi yang sedang maka perlu penelitian selanjutnya untuk mengetahui faktor lain yang mungkin akan mempengaruhi kelengkapan imunisasi dasar DPT anak di Desa Pamolaan Kabupaten Sampang.

\section{KESIMPULAN DAN SARAN \\ Kesimpulan}

Berdasarkan hasil penelitian yang telah dilakukan dapat disimpulkan sebagai berikut:

1. Dukungan keluarga yang diberikan kepada ibu untuk melengkapi imunisasi dasar DPT anak sebagian besar dalam kategori cukup dan dukungan keluarga yang paling kurang diberikan adalah dukungan informasi.

2. Peran keluarga dalam melengkapi imunisasi dasar DPT anak sebagian besar dalam kategori kurang dan peran yang paling kurang dirasakan adalah peran keluarga dalam mengenal masalah kelengkapan imunisasi DPT anak.

3. Dukungan keluarga berhubungan dengan kelengkapan imunisasi dasar DPT anak di Desa Pamolaan Kabupaten Sampang dengan tingkat korelasi sedang.

4. Peran keluarga berhubungan dengan kelengkapan imunisasi dasar DPT anak di Desa Pamolaan Kabupaten Sampang dengan tingkat korelasi sedang.

\section{Saran}

1. Bagi petugas kesehatan, khususnya kader posyandu dan perawat komunitas hendaknya lebih aktif lagi dalam memberikan informasi tentang jadwal pemberian imunisasi DPT maupun jadwal Posyandu misalnya melalui puskesmas keliling.

2. Bagi Puskesmas, hendaknya meningkatkan promosi kesehatan tentang imunisasi DPT yang memberi penjelasan secara aktif tentang pengertian, manfaat, akibat, efek samping, jadwal imunisasi DPT, dan cara perawatan anak setelah imunisasi DPT dengan melibatkan keluarga.

3. Bagi Dinas Kesehatan Kabupaten Sampang, hendaknya lebih dikembangkan lagi program-program untuk meningkatkan cakupan imunisasi DPT di Desa Pamolaan Kabupaten Sampang misalnya sosialisasi tentang imunisasi DPT dengan cara menggandeng tokoh masyarakat dan mengikutsertakan keluarga dalam sosialisasi tersebut. 
4. Bagi keluarga, hendaknya lebih aktif dalam memberikan dukungan dan peranan dalam melengkapi imunisasi dasar DPT anak misalnya dengan mengikuti setiap penyuluhan tentang imunisasi yang dilakukan oleh Puskesmas.

5. Bagi penelitian selanjutnya, diharapkan lebih fokus pada faktor dominan lain yang mempengaruhi kelengkapan imunisasi dasar DPT lain misalnya pengetahuan keluarga tentang pentingnya kelengkapan imunisasi dasar DPT anak.

\section{DAFTAR PUSTAKA}

Admin, dkk., (2008). Pencapaian Program Kesehatan.http: //www.purbalingga. go.id.Tanggal 12 Desember 2009. Jam 16.30

Arikunto, S., (2007). Manajemen Penelitian. Jakarta: Rineka Cipta, hal: 269

Azwar, S., (2005).Penyusunan Skala Psikologi. Yogjakarta: Pustaka Pelajar, hal: 109

Badan Penelitian dan Pengembangan Depkes RI, (2007).Laporan Riset Kesehatan Dasar Tahun 2007 Provinsi Jawa Timur. Jakarta: Departemen Kesehatan, hal: 65

Depkes RI., (2001). Studi Kesehatan Ibu dan Anak. http//:www.depkes.go.id. Tanggal 05 Maret 2010

Dinas Komunikasi dan Informatika, (2009).Hasil Cakupan Imunisasi Minim, Dinkes Gandeng MUI Dan Ormas.

http://www.jatimprov.go.id/index.php.

Tanggal 05 Maret 2010

Dinkes Sampang, (2009). Laporan Hasil imunisasi Per Puskesmas dan Kajiannya Kabupaten Sampang Bulan Januari s/d Desember 2009.Sampang: Dinas Kesehatan Kabupaten Sampang

Dinkes Surabaya, (2009). Evaluasi Millenium Coorporation Challenge Indonesia/Imunization Project (MCCl). http://www.surabayaehealth.org/category/katberita/berita/b erita-kesehatan. Tanggal 03 Maret 2010

Devit, K. S., (2007).Model Kepercayaan Kesehatan (Health Belief Model) terhadap Pelaksanaan Imunisasi di Posyandu. Skripsi untuk memperoleh gelar Sarjana Kesehatan Masyarakat UNAIR tidak dipublikasikan
Efendi, F. dan Makhfudli, (2009).Keperawatan kesehatan Komunitas Teori dan Praktik dalam Keperawatan. Jakarta: Salemba Medika,hal: 179-185

Ernoviana dan Mubasysyir, $\mathrm{H}$., (2006). Pemanfaatan Buku Kesehatan Ibudan Anak di Dinas Kesehatan Kota Sawahlunto. Working Paper Series No. 29, Universitas Gadjah mada, Yogyakarta

Friedman, (1998).Keperawatan Keluarga. Edisi 3. Jakarta: EGC, hal: 174, 299300

Green, L. and Judith M. O., (1999).Community and Population Health. Mc Graw: Hill Companies, hal: 100

IDAI, (2008). Jadwal Imunisasi 2008. http://www.idai.or.id.upload/jadwal08.p df. tanggal 09 Mei 2010

Kanvas Department of Health and Environment.Kansas Brfss Questionnaire.http://www.kdheks.gov/. Tanggal 24 April 2010

Mubarak, W. I., dkk, (2006).IImu Keperawan Komunitas 2. Jakarta: Sagung Seto, hal: 259-262

Newton, (2000).Family-Centered Care: Current realities in Parent Participation. Pediatric Nursing Article.http://www.highbeam.com/.

Tanggal 21 April 2010

Notoatmodjo, (2003).IImu Kesehatan Masyarakat. Jakarta: Rineka Cipta, hal 39-40

Notoatmodjo, (2005).Promosi Kesehatan. Jakarta: Rineka Cipta, hal: 66-79

Notoatmmodjo, (2007).Promosi Kesehatan dan IImu Perilaku. Jakarta: Rineka Cipta, hal: 178-179

Nursalam, (2008).Konsep dan Penerapan Metodologi Penelitian Keperawatan. Jakarta: Salemba Medika, hal: 97-98, 162

Ranuh, I.G.N dkk, (2005).Pedoman Imunisasi di Indonesia. Jakarta: Pengurus Pusat IDAI, hal: 32, 59, 65-72, 88-123

Rita, J., (2007). Mengenal Penyakit-Penyakit Balita dan Anak. Jakarta: Sunda Kelapa Pustaka, hal: 6

Riyanto, A., (2009). Pengelolaan dan Analisis Data Kesehatan. Yogjakarta: Nulia Medika, hal: 75

Sastrohadiwiryo, S., (2003).Manajemen Tenaga Kerja Indonesia.Jakarta: Bumi Aksara, hal: 13 
Setiadi, (2008). Konsep dan Proses Keperawatan Keluarga. Yogyakarta: Graha IImu, hal 13, 20-23, 96-97

Setiawati, I, dan Anita, Z., (2007). Sibling Rivalry Pada Anak Sulung yang Diasuh Oleh Single Father. Jurnal Psikologi, Vol 2. No 2, Hal: 46

Soetjiningsih.1995, Tumbuh Kembang Anak. Jakarta: EGC, hal: 10

Supraptini, dkk, (2003).Cakupan Imunisasi Balita dan ASI Esklusif di Indonesia, Hasil Survei Kesehatan Nasional (SURKESNAS) 2001.Jurnal Ekologi Kesehatan, Vol 2. No 2, Hal: 252

Tawi, M., (2008).Imunisasi dan Faktor yang Mempengaruhi.http://www. syehaceh.wordpress.com/. Tanggal 03 Maret 2010

Unicef, ( 2009). Pedoman teknis Imunisasi Tingkat Puskesmas. Dinas Kesehatan Kabupaten Sampang, hal: 1, 9-12, 119,121

Wahab, S., (2003).Sistem Imun, Imunisasi dan Penyakit Imun. Jakarta: Widya Medika, hal: 38, 44, 48, 50

Wasis, (2008). Pedoman Riset Praktis. Jakarta: EGC, hal: 47

Widiastuti, dkk, (2008).Analisis faktor yang berhubungan dengan Perilaku lbu dalam Memberikan Imunisasi Dasar Kepada Bayinya di Desa Banyutowo Kabupaten Kendal.Jurnal Analis Kesehatan Universitas Muhammadiyah Semarang, Vol 1. No. I Desember 2008 hal: 8-9 